\title{
A Reforma do Conselho de Segurança da ONU: Notas Preliminares ${ }^{1}$
}

The Reform of the UN Security Council: Preliminary Notes

Alexsandro Eugenio Pereira ${ }^{2}$

\section{RESUMO}

Recentemente, o G4 (grupo formado por Brasil, Alemanha, Japão e Índia) criticou o atraso da reforma do Conselho de Segurança das Nações Unidas (CSNU). Esse grupo de países defendeu a ampliação do número de membros permanentes do Conselho. Nesse artigo, argumento que as propostas sobre a reforma do Conselho não se mostraram capazes de enfrentar desafios mais complexos colocados às principais organizações internacionais do mundo contemporâneo.

Palavras-chave: Organizações Internacionais; Conselho de Segurança; Democracia.

\section{ABSTRACT}

Recently, the G4 (a group formed by Brazil, Germany, Japan and India) criticized the delay of the reform of the UN Security Council (UNSC). This group of countries called for expanding the number of permanent members. In this article, I argue that the proposals on the reform of the Council were not able to tackle the most complex challenges posed to the major international organizations of the contemporary world.

Key-Words: International Organization; Security Council; Democracy.

O G4, formado por Brasil, Alemanha, Japão e Índia, defendeu o aumento do número de membros permanentes do Conselho. Segundo a proposta original desse grupo de países, o Conselho passaria a ter dez novas cadeiras, sendo seis permanentes e quatro não permanentes. Além dos quatro países que integram o grupo, eles defenderam a inclusão de mais dois países da África. A proposta original foi adaptada. Hoje, o G4 defende a formação de um Conselho com dez membros permanentes. Inicialmente, a proposta do G4 sofreu oposição da China que discordou da inclusão do Japão como membro permanente.

\footnotetext{
${ }^{1}$ Artigo recebido em 08 de outubro de 2013 e aprovado para publicação em 13 de outubro de 2013.

2 Doutor em Ciência Política pela USP e Docente dos Programas de Pós-Graduação em Ciência Política e em Políticas Públicas da UFPR, Curitiba, Brasil.
} 
Ao lado dessa proposta, outras foram apresentadas a partir dos anos 1990. Em geral, a maior parte dessas propostas de reforma do Conselho de Segurança pretendeu enfrentar dois problemas fundamentais: a manutenção do poder de veto dos cinco permanentes (Estados Unidos, Rússia, China, França e Reino Unido); e a capacidade de tornar o CSNU mais compatível com a atual distribuição de poder existente nas relações internacionais. 0 poder de veto estabeleceu uma desigualdade entre os países no processo decisório do Conselho, na medida em que cinco Estados podem paralisar a tomada de decisões de acordo com suas posições e interesses políticos. Como resultado, o Conselho de Segurança apresentou dificuldades para produzir decisões, especialmente durante a Guerra Fria (1947-1989). Essas dificuldades fragilizaram o CSNU como instância fundamental da tomada de decisões na área de segurança internacional. Por isso, as recentes propostas de reforma do Conselho de Segurança envolveram uma discussão sobre a manutenção do poder de veto, pois esse mecanismo coloca os países membros do órgão em condições desiguais na tomada de decisões. Além disso, as propostas cogitaram a ampliação do número de países membros do órgão, procurando incluir dois dos principais financiadores das Nações Unidas (Japão e Alemanha) e potências reconhecidamente importantes nas esferas regionais, como o Brasil e a Índia. Persistiu, no entanto, a discussão sobre as condições nas quais esses novos membros poderiam ser incluídos. Em outros termos, se o poder de veto for mantido, os novos membros poderão utilizar esse mecanismo? Ou ele será extinto e todos os membros do Conselho terão peso idêntico no processo decisório?

Na prática, desde a sua criação em 1946, a única reforma realizada no Conselho aconteceu nos anos 1960 quando houve o acréscimo de membros não permanentes, elevando o número total de membros do órgão de onze para quinze. Nesse momento, o processo de descolonização gerou um consequente aumento do número de países membros das Nações Unidas e motivou a alteração promovida nos anos 1960. Em 1993, a Assembleia Geral das Nações Unidas estabeleceu um grupo de trabalho com o propósito de discutir a possibilidade de nova ampliação do Conselho de Segurança³.

As propostas de reforma giraram em torno da necessidade de ampliar o número de atores estatais, com ou sem direito a veto. De acordo com o conteúdo das propostas, o

\footnotetext{
${ }^{3}$ Intitulado Open-Ended Working Group on the Question of Equitable Representation and Increase in the Membership of the Security Council.
} 
órgão permaneceria intergovernamental. As propostas estavam baseadas em um pressuposto realista segundo o qual os Estados seriam os únicos atores relevantes capazes de encaminhar temas da agenda de segurança no mundo atual Em termos concretos, não houve qualquer discussão a respeito do aumento da influência de atores não estatais como as Organizações Não Governamentais (ONGs). Algumas dessas organizações fornecem ajuda humanitária em diversos conflitos internacionais. A partir de 2006, as ONGs passaram a desempenhar um papel consultivo nas sessões públicas do Conselho. Esse papel foi estabelecido pelas medidas de transparência adotadas pelo órgão. Com exceção desse papel, as ONGs ou outros atores não estatais não terão qualquer possibilidade de participar mais ativamente do processo decisório do órgão.

Em termos práticos, a manutenção do atual formato do processo decisório dentro do Conselho gera discrepâncias quanto à representação dos interesses políticos de atores estatais do sistema internacional, gerando questionamentos sobre a legitimidade do órgão e sobre a natureza das suas decisões. Em outras palavras, a estagnação da reforma do Conselho não tem implicações apenas para os países que desejam ocupar assentos permanentes no CSNU, como é o caso do G4 mencionado acima. Ela compromete a própria capacidade do órgão representar interesses presentes na atual configuração de poder do sistema internacional Ao comprometer essa capacidade, a estagnação da reforma coloca em xeque qualquer possibilidade de democratização do órgão por meio da superação do seu anacronismo. Com isso, ele permanece inadequado diante das características atuais da política internacional que foram abordadas por uma literatura produzida a partir dos anos $1970^{4}$.

Além desse problema, o CSNU não seria compatível com a própria natureza da democracia atual de acordo com a interpretação de David Held (1991) sobre o que ele chamou de "democracia global". Held identificou uma mudança substantiva na soberania estatal como consequência: $(i)$ da crescente interdependência econômica e política entre os Estados; (ii) do rápido desenvolvimento de ligações transnacionais; e (iii) da formação de blocos de poder regionais. Embora não sustente o desaparecimento do Estado territorial, Held sustentou que haveria uma alteração no grau de autonomia dos Estados

\footnotetext{
${ }^{4}$ Conferir, a esse respeito, KEOHANE e NYE, 2001; KEOHANE e NYE Jr., 1972; DEUTSCH, 1978; MERLE, 1981; KAISER, 1990, dentre outros. Sobre a reforma do Conselho de Segurança, conferir, dentre outros, BOULDEN, 2006; HERZ, 1999; MORRIS, 2000; WEISS, 2003.
} 
como consequência do processo de globalização. Essa alteração modificaria, ainda segundo o autor, o lócus da decisão política que seria gradualmente transferido para organizações intergovernamentais e supranacionais. Held argumentou que as transformações recentes nas relações internacionais afetaram a capacidade estatal de exercer autoridade política dentro do seu território. Dessa forma, as atividades e responsabilidades do Estado nacional não poderão mais ser realizadas sem a colaboração internacional de outros atores estatais e mesmo não estatais. Em decorrência dessa situação, as Organizações Internacionais passariam a ter um papel fundamental. Held considerou que a globalização criou cadeias de decisões políticas e resultados interligados entre os Estados e seus cidadãos, o que gerou alterações na natureza e na dinâmica dos próprios sistemas políticos nacionais. (cf. HELD, 1991, p. 179).

As considerações de Held sugerem que a democracia foi ampliada para além dos limites dos Estados nacionais. Nesse sentido, Robert Dahl (1994) afirmou que o período atual seria caracterizado pela "transnacionalização da democracia" em virtude das transformações recentes mencionadas por Held. No entanto, ao contrário desse autor, Dahl considerou que é necessário aprimorar as instituições políticas domésticas com o propósito de reforçar a compreensão e a participação informada dos cidadãos dos Estados nacionais. Held, ao contrário, identificou um processo de transferência do lócus da decisão política, conforme foi apontado antes. Ao mesmo tempo, destacou como as características atuais das relações internacionais e a complexidade dos temas da agenda internacional produziram dificuldades relacionadas à construção de instituições políticas no plano internacional. Essas instituições precisariam ser adequadas para processar demandas variadas, viabilizar a participação e a representação política de atores estatais e não estatais e tornar suas decisões legítimas.

Aceitando os termos de Held, o debate sobre a reforma do Conselho de Segurança é muito mais complexo do que a simples discussão sobre a manutenção do poder de veto ou sobre a inclusão de novos Estados à sua composição. Envolve um desenho institucional que seja compatível com: (i) a natureza da agenda internacional na atualidade; (ii) a presença de interesses de atores societais nessa agenda, como ONGs, grandes corporações transnacionais, dentre outros atores; e (iii) a capacidade de tornar esse desenho compatível com o problema da legitimidade e da eficácia das organizações internacionais. 
Assim, apesar da natureza específica dos temas de segurança internacional, que sempre envolverão a participação e o envolvimento decisivos dos Estados, a reforma do Conselho de Segurança não passa apenas pela capacidade de representar os diversos interesses políticos e estatais do sistema internacional. Ela envolve uma redefinição do papel das organizações intergovernamentais num contexto internacional crescentemente complexo. Por isso, os desafios são muito mais complicados, ao contrário do que sugerem as propostas de reforma do CSNU formuladas desde os anos 1990.

\section{Referências}

BOULDEN, Jane. Double Standards, Distance and Disengagement: Collective Legitimization in the Post-Cold War Security Council. Security Dialogue, vol. 37, n. 3, September 2006.

DAHL, Robert. A Democratic Dilemma: System Effectiveness versus Citizen Participation. Political Science Quarterly, vol. 109, 23-34, 1994.

DEUTSCH, Karl. Análise das relações internacionais. Brasília: Editora da UnB, 1978.

HELD, David. Democracia, o Estado-nação e o sistema global. Lua Nova, São Paulo, no 23, 1991.

HERZ, Mônica. O Brasil e a reforma da ONU. Lua Nova, São Paulo, no 46, 1999.

KAISER, Karl. A política transnacional: Para uma teoria da política multinacional. In: BRAILlARD, P. Teoria das relações internacionais. Lisboa: Fundação Calouste Gulbekian, 1990.

KEOHANE, Robert e NYE Jr., Joseph. Transnational Relations and World Politics. Cambridge: Harvard University Press, 1972.

KEOHANE, Robert O.; NYE, Joseph S. Power and Interdependence. New York: Longman, 2001.

MERLE, Marcel. Sociologia das relações internacionais. Brasília: Editora da UnB, 1981.

MORRIS, Justin. UN Security Council Reform - A Counsel for the 21st Century. Security Dialogue, vol. 31, n. 3, September 2000.

WEISS, Thomas G. The Illusion of Un Security Council Reform. The Washington Quarterly, 26:4, p.147-161, 2003. 